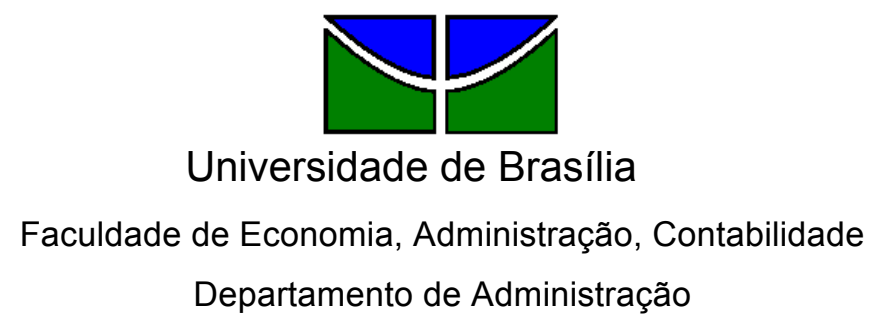

Departamento de Administração

ADENIKE ABIODUN ANEYS AJAGUNNA

TAXA DE OCUPAÇÃO EM HOTELARIA: relação dos eventos e preços com o controle de efeitos sazonais

Brasília - DF

2010 


\section{ADENIKE ABIODUN ANEYS AJAGUNNA}

\section{A TAXA DE OCUPAÇÃO EM HOTELARIA: relação dos eventos e preços com o controle de efeitos sazonais}

Monografia apresentada ao

Departamento de Administração como requisito parcial à obtenção do título de Bacharel em Administração.

Professor Orientador: Dr. Rafael Barreiros Porto

Brasília - DF 
Ajagunna, Adenike Abiodun Aneys.

Análise da Gestão Estratégica e Mercadológica do Hotel Meliá Brasil 21 / Adenike Abiodun Aneys Ajagunna. - Brasília, 2010.

$40 \mathrm{f}$. : il.

Monografia (bacharelado) - Universidade de Brasília, Departamento de Administração, 2010.

Orientador: Prof. Dr. Rafael Barreiros Porto, Departamento de Administração.

1. Vendas em Hotelaria. 2. Influência de preço em Hotelaria. 3. Eventos em Hotelaria. 4. Hotelaria no Distrito Federal. 5. Sazonalidade I. Título 


\title{
TAXA DE OCUPAÇÃO EM HOTELARIA: relação dos eventos e preços com o controle de efeitos sazonais
}

\begin{abstract}
A Comissão Examinadora, abaixo identificada, aprova o Trabalho de Conclusão do Curso de Administração da Universidade de Brasília da aluna
\end{abstract}

\section{Adenike Abiodun Aneys Ajagunna}

Dr. Rafael Barreiros Porto

Professor-Orientador

Msc. Pedro Henrique Melo Albuquerque

Késia Rozzett

Professor-Examinador

Professor-Examinador

Brasília, 01 de setembro de 2010 
Dedico à minha mãe, mulher forte e guerreira, que sempre me incentivou a ser melhor que poderia, com amor e gratidão. $E$, às minhas irmãs, por todo apoio e compreensão. 


\section{AGRADECIMENTOS}

À Deus, pela vida e pelo amor incondicional.

Ao meu orientador Dr. Rafael Barreiros Porto, por ser inigualável e excepcional no seu trabalho, pelas relevantes sugestões e constante atenção.

À professora Késia Rozzett por todo seu empenho, dedicação e amparo nas horas difíceis.

Aos meus amigos pela mão estendida e o ombro cedido.

À gerência do Hotel Meliá Brasil 21, por tornar minha pesquisa viável. 


\section{RESUMO}

O presente trabalho objetiva analisar se a estratégia de precificação e de realização de eventos em um hotel influenciam sua taxa de ocupação de clientes. Para tanto, foram analisadas as variáveis preço médio efetivo pago pelo hóspede, sazonalidade diária, sazonalidade mensal e eventos realizados no Centro de Eventos do mesmo complexo que o Hotel. Os dados foram coletados do sistema da empresa estudada e montado um banco de dados para ser feita análise da regressão múltipla. Além da análise individual das variáveis, foi feito o controle das variáveis de sazonalidade a fim de investigar melhor o impacto do preço e eventos na taxa de ocupação. A análise concluiu que os eventos possuem grande impacto e são o maior responsável pelo aumento da taxa de ocupação. A partir dos resultados obtidos, orienta-se futuras pesquisas em hotelaria com foco na análise da taxa de ocupação e atenção, por parte dos gestores do Hotel, para a realização de eventos para que captem reservas e assim aumentem sua taxa de ocupação.

Palavras-chave: Taxa de ocupação hoteleira, eventos em hotelaria, sazonalidade. 


\section{LISTA DE ILUSTRAÇÕES}

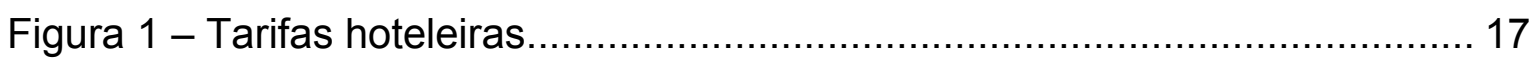

Figura 2 - Modelo empírico da pesquisa...................................................... 23

Figura 3 - Processo de precificação e definição de lucros..................................32 


\section{LISTA DE TABELAS}

Tabela 1 - Derivado do Modelo Empírico .................................................... 23

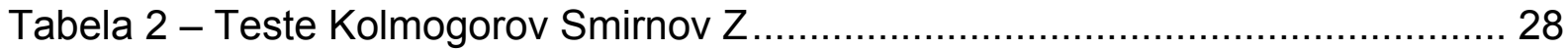

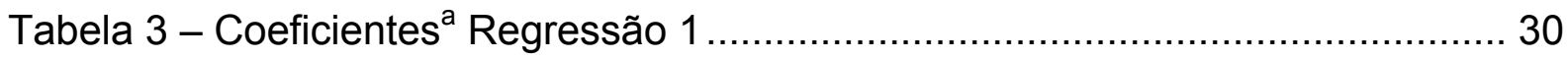

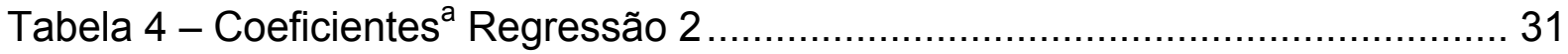




\title{
LISTA DE ABREVIATURAS E SIGLAS
}

\author{
ABIH - Associação Brasileira da Indústria Hoteleira \\ BRASILIATUR - Empresa Brasiliense de Turismo \\ BCVB - Brasília Convention \& Visitor's Bureau \\ EMBRATUR - Instituto Brasileiro de Turismo \\ FCVBB - Fórum dos Convention \& Visitor's Bureau Brasil \\ ICCA - International Congress and Convention Association \\ OMT - Organização Mundial do Turismo \\ UH - Unidade Habitacional
}




\section{SUMÁRIO}

1 INTRODUÇÃO

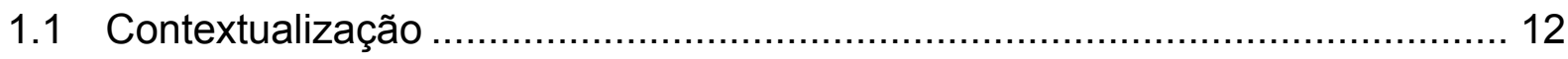

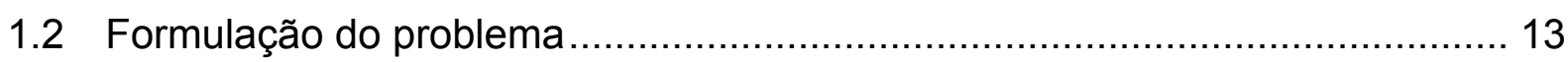

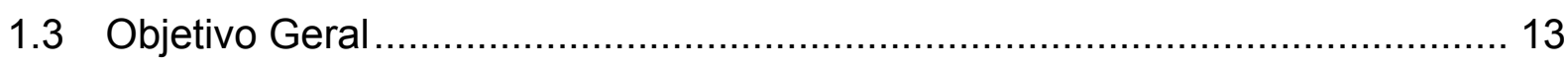

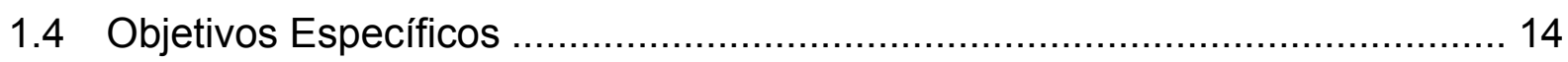

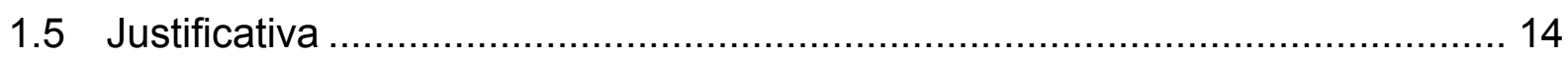

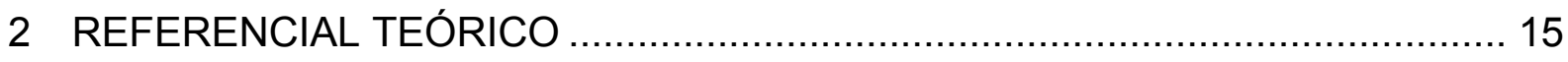

2.1 Vendas (taxa de ocupação) em Hotelaria ..................................................... 15

2.2 Influência de preço (precificação) em Hotelaria ............................................... 16

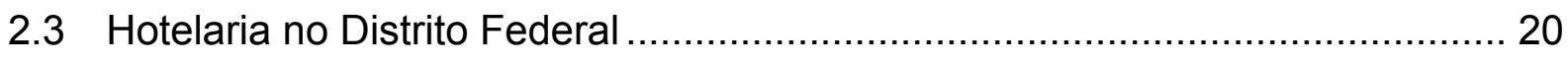

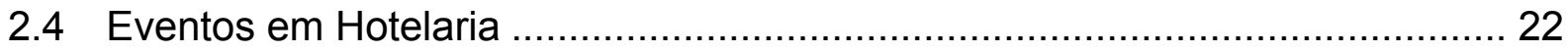

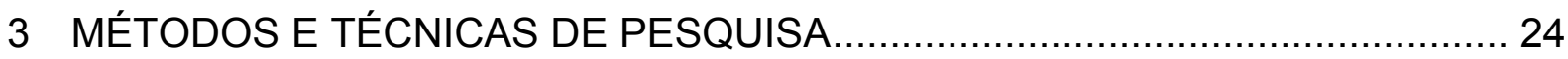

3.1 Tipo e descrição geral da pesquisa .......................................................... 24

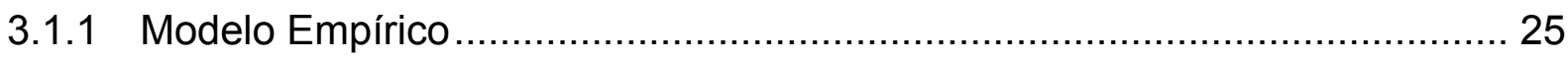

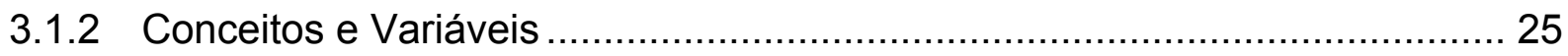

3.2 Caracterização da organização, setor ou área ............................................. 26

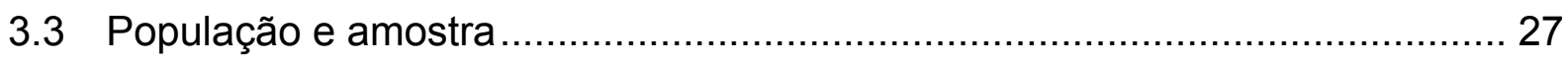

3.4 Caracterização dos instrumentos de pesquisa ............................................. 28

3.5 Procedimentos de coleta e de análise de dados ............................................ 29

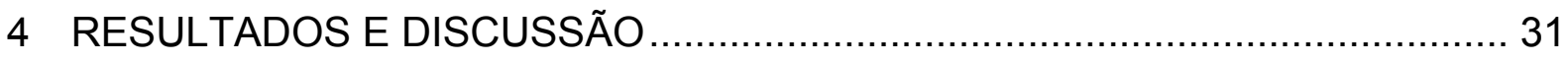

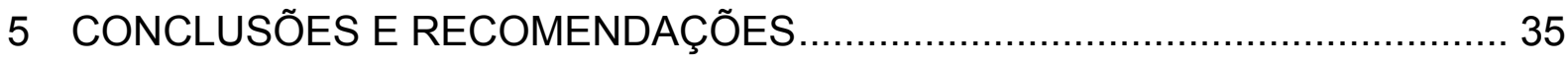

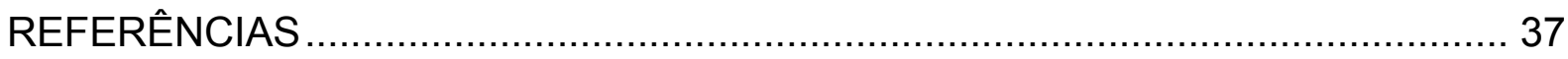

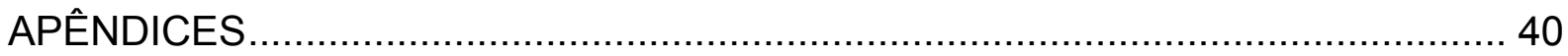

Apêndice A - Organograma do Hotel Meliá Brasil 21 ........................................... 40 


\section{INTRODUÇÃO}

O Turismo é um dos setores da economia que vem se destacando cada vez mais no contexto sócio-econômico. A atividade turística exige uma estrutura específica para servir de apoio ao turista em sua estada: os meios de hospedagem. Incluem-se neste setor pousadas, albergues, motéis, flats, apart-hotéis, hotéis, dentre outros empreendimentos de diferentes categorias, que variam desde unidades mais simples às mais elegantes e sofisticadas atendendo aos mais variados perfis de turistas. O Brasil vem ganhando destaque internacional no ramo do turismo de negócios e viagens de incentivo, promovidas por grandes empresas de todo o mundo. Tem sido um dos destinos mais escolhidos para sediar feiras, congressos, convenções ou exposições de todos os tipos. Além de possuir estrutura adequada para abrigar eventos, o país ainda pode oferecer as mais variadas opções de lazer cultural, natural e artístico, unindo o útil ao agradável (Instituto Brasileiro de Turismo - EMBRATUR, 2010).

Segundo informações da Empresa Brasiliense de Turismo (BrasíliaTur), o turista de negócios, congressos ou convenções representa $71,4 \%$ do desembarque nacional e $45,4 \%$ do desembarque internacional de passageiros em Brasília e o Brasil ocupa o $7^{\circ}$ lugar como destino de eventos internacionais no ranking da ICCA (International Congress and Convention Association), a maior entidade internacional do segmento de meetings do mundo.

O turismo de negócios é o principal foco dos investimentos hoteleiros no Brasil. É para este público que está sendo voltado o maior número de investimentos. Uma das estratégias é o oferecimento de hospedagens econômicas onde o fator chave é a relação custo-benefício para o consumidor, atendendo aos desejos das empresas de redução de custos com hospedagem de funcionários.

Conforme dados obtidos da Associação Brasileira da Indústria de Hotéis - DF (ABIH/DF), o turista de negócios representa $64 \%$ da taxa de ocupação dos hotéis da cidade. O desenvolvimento deste segmento vem sendo amparado por um crescimento paralelo do parque hoteleiro, que se aparelha para atender a este nicho 
de mercado. Atualmente, Brasília conta com 47 empresas que prestam serviços de hospedagem registrados oficialmente como hotéis.

Consciente do aumento da concorrência, as empresas vêm valendo-se de técnicas de marketing cada vez mais modernas para atrair o consumidor final. De acordo com Lepsch e Souza (2007, p. 174): "O preço é a variável do mix de marketing de maior relevância nos resultados econômico-financeiros...". Essa variável foi apontada como item de importância na escolha de hotéis (KANDAMPULLY; SUHARTANTO, 2000; LOCKYER, 2005). Logo, se por um lado o preço é o principal fator de resultado para a empresa, por outro ele é um dos principais fatores de interesse do cliente no momento da escolha de hotéis, assim sendo, requer habilidade em sua gestão. Assim como para um turista de negócio ou eventos a localização e proximidade do hotel escolhido ao local do evento realizado é um dos fatores que apresenta maior correlação, conforme estudos de Ignarra (2007, p.131).

\subsection{Contextualização}

As empresas e os profissionais necessitam, para o desenvolvimento de suas atividades e negócios, efetuar freqüentes viagens que possibilitem o contato com pessoas, organismos e empresas, dos quais poderá obter o início, a continuação ou a conclusão de uma atividade ou negócio. O incremento do turismo de negócios deve ser tratado como vital para o crescimento econômico de qualquer país, pois, além da receita proporcionada ao segmento turístico, o viajante de negócios, uma vez satisfeito nas necessidades cobertas pelo setor turístico, estará disposto a incrementar suas atividades no país, trazendo investimentos para a economia e gerando um efeito multiplicador, tanto pelas visitas mais freqüentes que fará, quanto pelas impressões positivas que leva para sua região, tornando um agente de marketing confiável e modificador de opiniões perante sua comunidade. É fundamental que se dê a esse segmento a importância necessária para que ele se incremente. Encontra-se nesse trabalho atenção voltada para um hotel que abriga os turistas de negócios, a fim de entender qual o impacto e sua intensidade do preço e da ocorrência de eventos na taxa de ocupação em um hotel da cidade de Brasília. 


\subsection{Formulação do problema}

A ocupação dos hotéis em Brasília é dependente do turismo de negócios ou eventos, sendo a maior responsável pela alta ocupação durante a semana (cerca de $89 \%$ ), de segunda a quinta e aos finais-de-semana, a ocupação cai para $25 \%$, conforme dados obtidos na ABIH/DF.

O preço é um dos componentes mais sensíveis do composto mercadológico pois influencia diretamente a receita da empresa, contribui com seu lucro, com sua imagem e com sua participação (CHAN; WONG, 2006). Apesar dessa significância do preço como um elemento de marketing estratégico, a precificação é negligenciada em função de sua variação (NAGLE; HOLDEN, 1995).

O preço pode sofrer alterações de acordo com o momento da demanda. Por exemplo, a indústria da hospitalidade estabelece tarifas inferiores em baixa temporada. Compreender a relação elasticidade-preço é fundamental nas decisões de apreçamento, ou seja, a alteração no preço pode afetar a demanda e, consequentemente, a taxa de ocupação (LOVELOCK, 1996).

Além do preço, os eventos podem influenciar a taxa de ocupação de um hotel quando os participantes de outras localidades demandam por infra-estrutura adequada para recebê-los. A importância dos eventos na demanda do serviço de hospedagem pode ser observada pelas taxas de ocupação hoteleiras da cidade que aos finais de semana se mostram bem inferiores às dos dias úteis (IGNARRA, 2007).

Levando-se em consideração os pontos apresentados acima, a seguinte questão foi definida para originar o trabalho: qual estratégia de marketing gera maior impacto na taxa de ocupação: precificação da unidade habitacionais ou eventos realizados pelo complexo onde está inserido o hotel? 


\subsection{Objetivo Geral}

O trabalho tem por objetivo analisar se a estratégia de precificação e de realização de eventos em um hotel influenciam sua taxa de ocupação.

\subsection{Objetivos Específicos}

1. Analisar a relação preditiva entre preço pago, realização de eventos e sazonalidade na taxa de ocupação de unidades habitacionais do Hotel;

2. Analisar a relação preditiva entre preço pago e realização de eventos na taxa de ocupação de unidades habitacionais do Hotel, em diferentes períodos de sazonalidade.

\subsection{Justificativa}

A escolha por este tema justifica-se pela ausência de informações concretas acerca dos resultados advindos das estratégias de preço no Hotel Meliá Brasil 21. Torna-se difícil alguma mudança na gestão quando não há dados suficientes sobre a eficiência dos métodos utilizados. Há carência de estudos de precificação em empresas que utilizam múltiplos canais para vender seus produtos (YAN, 2008). Alguns estudiosos vêm abordando a hotelaria em suas pesquisas de avaliação dos fatores de escolha de um hotel (AGGETT, 2007; CARVELL; QUAN, 2008; CHAN; WONG, 2006), porém existem poucos trabalhos relacionando esses fatores determinantes da escolha ao desempenho econômico-financeiro de hotéis, assim como as variáveis preço e taxa de ocupação. 


\section{REFERENCIAL TEÓRICO}

O referencial teórico está estruturado em quatro partes: a primeira parte é sobre as vendas em hotelaria, especificamente $o$ índice que define e explicita em termos gerais como estão sendo vendidas as unidades habitacionais do hotel. A segunda seção é sobre a influência dos preços em hotelaria, onde explica-se o que é e como é definido o preço em hotéis. A terceira parte é um panorama do setor hoteleiro no Distrito Federal. A quarta e última divisão fala sobre eventos em hotelaria e seu impacto nesse setor.

\subsection{Vendas (taxa de ocupação) em Hotelaria}

$\mathrm{Na}$ avaliação mercadológica de um hotel, um dos principais fatores de avaliação é a de taxa de ocupação. Essa taxa é responsável por providenciar meios detalhados, consistentes e contínuos para mensuração e monitoramento de sazonalidade na hotelaria (JEFFREY; BARDEN, 1999). A taxa de ocupação informa a porcentagem de unidades habitacionais ocupadas durante um período pelo hóspede.

Conforme Rathsmann (apud WEISE, 2006, p.5) taxas acima de $80 \%$ são excelentes e poucos hotéis têm isso. Um taxa de ocupação maior significa um hotel com mais atrativo e mais valorizado pelas acomodações e serviços adicionais. Taxas abaixo de $20 \%$ são muito perigosas para o futuro de um hotel, não apenas pela avaliação que faz com que este hotel valha menos, mas porque este hotel vai ser menos lucrativo. Porcentagens acima de $95 \%$ e menores de $10 \%$ são raros na ocupação hoteleira.

A taxa de ocupação (to) multiplicada pelos preços ( $p$ ) dos quartos e pelo número de dias (d) por ano, mais os serviços (s) é igual ao rendimento bruto anual (Rba), o que é mostrado na seguinte fórmula: 


\section{Fórmula 1: Fórmula da Taxa de Ocupação}

$$
\operatorname{Rba}=p^{*} d^{*} \text { to }+s
$$

É a partir da análise do retorno e rentabilidade do empreendimento, permitindo também a verificação e controle da sazonalidade de ocupação, que pode-se ter uma visão concreta e rápida com relação, por exemplo, à oferta de tarifas competitivas em relação ao mercado e também a uma análise do nível de aceitação que o empreendimento está tendo em relação ao mercado e seus concorrentes.

A taxa de ocupação também permite medir a influência de outros fatores além do preço, como localização, status (escolha do cliente) e a proximidade de locais de abrigo para eventos. Pesquisas demonstram que, geralmente, a realização de eventos no hotel ou próximo ao hotel escolhido aumentam e possuem maior impacto nas taxas de ocupação que a variável preço (ALMEIDA, 2004; IGNARRA, 2007).

\subsection{Influência de preço (precificação) em Hotelaria}

A tomada de decisão dentro do âmbito empresarial consiste na escolha da opção dentre cursos alternativos que melhor se enquadre dentro de seus interesses. Sardinha (1995) define preço como a quantidade de dinheiro que o consumidor desembolsa para adquirir um produto e que a empresa recebe em troca da cessão do mesmo. Portanto, preço pode ser definido como o montante monetário pago pelo usuário final (consumidor) ao prestador de serviços (fornecedor), para satisfazer suas necessidades, enquanto este visa obter lucro ou retorno financeiro.

Ressaltam Horngren, Datar e Foster (2004) que o preço de um produto ou serviço depende da demanda e oferta. Os fatores que influenciam a demanda e oferta são os clientes e os concorrentes. Os clientes influenciam a formação do preços quando analisam o valor cobrado pelo serviço disponível e os benefícios que poderão vir a ter caso adquiram-nos, ou seja, a relação custo $x$ beneficio. Os consumidores consideram suas preferências, gostos e desejos em termos de avaliação dos benefícios recebidos pelo preço efetivamente pago. Assim, serviços semelhantes 
tendem a ter preços semelhantes pois o melhor em serviços não é cobrar preços inferiores, mas diferenciar o produto ofertado, para que ele valha um preço superior.

A política de apreçamento de serviços leva em conta o perfil do cliente, o produto, a natureza e o local da venda e os concorrentes (NAGLE; HOLDEN, 2003). Os preços dos concorrentes podem afetar os preços cobrados por uma empresa. Produtos alternativos ou similares podem afetar a demanda e forçar uma empresa a baixar seus preços. Por outro lado, uma empresa livre de concorrência, imersa em monopólio, pode elevar seus preços sem grandes problemas. A precificação também varia de acordo com o mercado. Sardinha (1995) comenta que, no curto prazo, o preço cobrado pela prestação de um serviço pode ser influenciado pelo mercado, mas a sobrevivência de uma empresa no longo prazo depende de suas decisões sobre políticas consistentes de preço.

Bruni e Famá (2003) destacam que o retorno do capital dá-se por meio de lucros conseguidos ao longo do tempo. Assim, através de uma correta política de apreçamento se consegue firmar o retorno certo do investimento realizado. Além dos consumidores, concorrentes e custos, que influenciam na precificação, a conjuntura econômica como recessão, inflação e taxas de juros, o governo e os aspectos sociais e legais também devem ser levadas em conta.

Watchravesringkan e Yurchisin (2007) indicam que os preços podem desempenhar dois papéis, positivo ou negativo, que influenciam o aumento ou a redução da possibilidade de compra. Se um cliente avaliar o preço de um serviço como um valor justo pelos benefícios que terá, ele poderá vir a adquirir o serviço; do contrário, a possibilidade de compra é mínima.

O preço é um fator importante para atrair consumidores, podendo-se utilizar diferentes estratégias de preço: psicológico, prestígio, penetração. Esses autores também relatam que, devido à forte concorrência nos mercados, a redução de preços é comumente utilizada pelas organizações (CHAN; WONG; 2006).

Em pesquisa realizada por Teixeira (2004) com proprietários de pequenos hotéis de Sergipe, o preço foi visto como atributo diferenciador para $30 \%$ dos proprietários que consideram seu preço melhor do que o dos concorrentes e que os clientes o percebem como vantajoso pela qualidade do serviço que oferecem. O preço e a 
qualidade dos serviços são vistos pelos proprietários como importantes vantagens competitivas. Os preços em hotelaria variam muito, dependendo da estação, da localização, das instalações e dos serviços oferecidos. Nos meses de março a junho e agosto a novembro, é quando os preços atingem o seu ponto máximo. Existem preços para quartos de solteiro, de casal, e descontos especiais para a baixa estação (finais de semana e os meses de julho e dezembro a fevereiro) e períodos de permanência maiores, mas, de forma geral, há negociação na redução de preço (TEIXEIRA, 2004, p.10-11).

$\mathrm{Na}$ hotelaria, preço leva o nome de tarifa, e se diferencia dos outros elementos existentes no hotel pois gera receita enquanto os demais geram custos. Estabelecida com base no valor de custo estimado de cada unidade habitacional (UH), o preço que o cliente paga por uma unidade habitacional (UH) varia entre a tarifa balcão ou rack rate - valor máximo, e a tarifa final - valor acordado. Esta variação se dá através de descontos que podem ter como critério o período da estada, de um dia a um mês, ou através de concessões de tarifas especiais para "cliente especiais" (LARA, 2001).

As tarifas são estabelecidas, pelo departamento de vendas do hotel ou em última instância, pela própria recepção, baseada na negociação feita com o cliente potencial. Segundo Lara (2001), as tarifas se dividem em (figura 1):

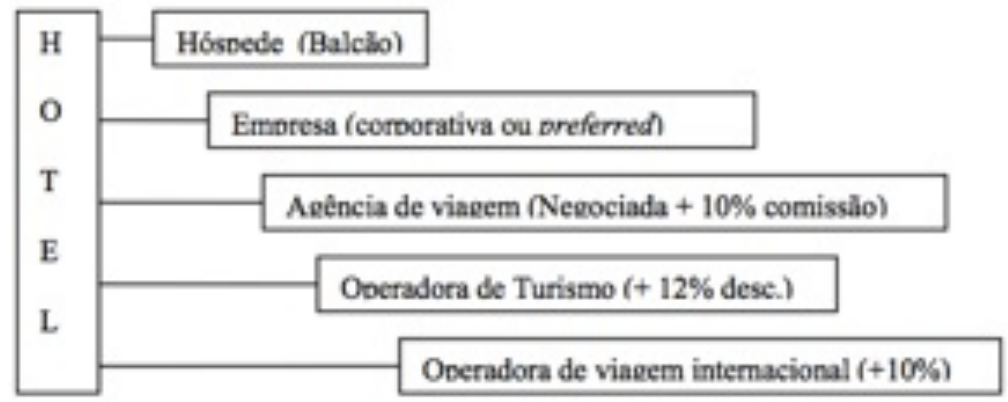

Figura 1: Tarifas Hoteleiras

Fonte: LARA, 2001

a) Tarifa Balcão/Rack Rate - a mais alta variando com as categorias existentes, ela é utilizada como referência para todos os descontos praticados;

b) Corporativa - considerada a mais competitiva tem o objetivo de ficar abaixo da tarifa da concorrência, como forma de atrair o mercado, principalmente, viajantes a negócios; 
c) Preferencial - tarifa corporativa preferencial concedida a empresas que já apresentam ou tem potencial de grande volume de consumo. Quanto maior for o volume da empresa, menor será sua tarifa.

d) Operadora de Turismo - a tarifa concedida por margem de lucro e comissão paga à agencia de viagem que distribuirá seu produto e normalmente recebem mais $12 \%$ de desconto em cima da tarifa preferencial.

e) Operadora de viagem Internacional - tarifa de operadora de turismo acrescida de, pelo menos, $10 \%$.

f) Outras tarifas - soft open (utilizada nos primeiros meses de funcionamento do hotel, para atrair cliente), fim de semana, de tripulação, de grupo, governamental, embaixadas, para mensalistas, etc. (LARA, 2001)

O conceito de revenue Management é receita por apartamento. A tarifa aplicada é determinada de acordo com seus padrões de demanda e oferta e com os da concorrência. Quando a demanda é forte e superior a oferta, os preços tendem a aumentar. Ao contrário, quando a demanda cai a tendência é baixar os preços, sempre respeitando as tarifas já acordadas (LARA, 2001).

\subsection{Hotelaria no Distrito Federal}

Brasília vem conquistando importância significativa no ramo da hotelaria, em detrimento da política e economia, para a realização de importantes eventos e congressos. A cidade planejada para ser capital política, centro administrativo do Brasil, abriga redes nacionais e internacionais de hotéis, conforme dados da $\mathrm{ABIH} / \mathrm{DF}$. É considerada um grande potencial para o turismo de eventos e negócios pois apresenta estrutura moderna e diversificada que permite a realização de congressos, feiras, exposições, convenções, shows, palestras, em âmbito nacional e internacional (BRASÍLIATUR, 2010).

Segundo o Brasília Convention e Visitors Bureau (BCVB), o hóspede de Brasília tem como motivação na sua vinda à cidade o trabalho, os negócios, a participação em eventos. O hóspede de negócios que vem do exterior tem preferência por hotéis que 
apresentam alta qualidade de serviços, e em especial, os que pertencem ou são administrados por uma rede internacional, já que estes mantêm o mesmo padrão de serviços em todo o mundo, proporcionando uma estada que enquadra-se dentro das expectativas conhecidas e experiência adquiridas. Os hóspedes de negócios nacionais como os estrangeiros, dão extrema importância à localização do hotel, em relação ao centro da cidade, tendo em vista a facilidade de deslocamento para o ambiente de trabalho.

$\mathrm{Na}$ escolha do hotel para o hóspede de negócios, muitas vezes quem escolhe é ele mesmo; outras vezes, a escolha é atribuída a uma secretária, que cuida das viagens corporativas do chefe limitada a um orçamento previamente estipulado; ou influência dos colegas da empresa. Essa escolha é englobada no universo de demanda do setor hoteleiro, que pode ser definida como a quantidade de bens e serviços turísticos que os consumidores desejam (LAGE; MILONE, 2000, p.26).

Existe na hotelaria, como em todo mercado, a oferta e demanda. O desencontro entre a demanda e a oferta é caracterizado como sazonalidade.

De acordo com Teixeira (1991, p.53),

a sazonalidade implica em mudanças no fluxo turístico tanto em relação ao volume quanto à direção escolhida. Chama-se, pois, alta estação ou alta temporada os períodos de maior procura pelo turismo; e baixa estação ou baixa temporada aqueles onde existe pouca procura.

A hotelaria, assim como o turismo em geral, sofre com a sazonalidade. Segundo Canton (2004, p.313), a área de eventos dentro de um hotel é de grande importância. Através desse produto, também ferramenta de marketing hoteleiro, o hotel pode tornar-se mais conhecido, alavancar novos negócios e conseqüentemente incrementar as receitas e as taxas de ocupação.

Para tanto, faz-se necessário que a unidade hoteleira esteja equipada para essa finalidade. Seguindo essa tendência de mercado, é difícil encontrar um hotel sem um espaço adequado para promoção de eventos. O centro de eventos passou a ser tido como produto indispensável para a sobrevivência dos hotéis nas principais cidades do mundo e fundamental para a solução do problema da sazonalidade (CANTON, 2004). 
$\mathrm{Na}$ conjuntura atual, os eventos funcionam como mecanismos de geração de demanda para os estabelecimentos hoteleiros. Estendendo essa discussão, percebe-se que a ocorrência desta sazonalidade ocorre, em partes, devido a uma falta de diversificação nas opções de mercado. Normalmente, as localidades brasileiras focalizam seus esforços em função de um único objetivo, não contemplando outras propostas viáveis que poderiam ser aproveitadas e que neutralizariam a vulnerabilidade da atividade.

À luz dessa discussão, a utilização dos eventos como estratégia do mercado hoteleiro no combate à sazonalidade vem recebendo adesão de uma fatia cada vez maior do mercado, na busca pela estabilidade e, conseqüentemente, benefícios permanentes.

\subsection{Eventos em Hotelaria}

O conceito de evento é amplo. De acordo com o SENAC (2000, p.45) evento é "qualquer acontecimento que foge à rotina, sempre programado para reunir um grupo de pessoas". Para Britto e Fontes (1997, p.17):

eventos são todos os acontecimentos previamente planejados, organizados e coordenados de forma a contemplar o maior número de pessoas em um mesmo espaço físico e temporal, com informações, medidas, projetos sobre uma idéia, ação ou produto, apresentando os diagnósticos de resultados e os meios mais eficazes para se atingir determinado objetivo.

A Organização Mundial do Turismo (OMT) diagnosticou a evolução do turismo de eventos (2003, p.145):

Cada vez mais, as empresas estão refletindo sobre a realização de encontros através de um processo de avaliação de necessidades. Este procura garantir que haja a compreensão de todos os participantes quanto às questões e aos objetivos dos encontros propostos e que fiquem claramente definidos os critérios para avaliar o sucesso ou a eficácia dos eventos.

Segundo Andrade (1999, p.31) os eventos constituem parte significativa na composição do produto turístico, atendendo intrinsecamente as exigências de mercado em matéria de entretenimento, lazer, conhecimento, descanso e tantas 
outras motivações.

De acordo com Goeldner, Ritchie e Mclntosh (2002, pg. 131) os eventos e as convenções constituem uma grande razão para as viagens de negócios. O mercado de eventos é um forte estimulador para o crescimento da demanda hoteleira. Tal fator ocorre não só em função dos espaços de eventos implantados dentro dos estabelecimentos hoteleiros, mas também em função da implantação dos centros de convenções e de exposições externos. Segundo Chon e Sparrowe (2003, pg. 260) durante os últimos 25 anos, os centros de convenções foram sinônimo de expansão da indústria hoteleira. Ou seja, o mercado de eventos apresenta grande crescimento no mundo.

A ociosidade dos equipamentos hoteleiros observada nos períodos de baixa estação representa grande ameaça e riscos à rentabilidade e sobrevivência no mercado. Enquanto estratégia, os eventos na hotelaria têm a capacidade de transformar esta situação em oportunidade de negócio. Os eventos surgem e se efetivam na garantia da ocupação hoteleira nos períodos de menor afluência turística e na solução do problema de certos núcleos, incapazes de garantir níveis de desempenho que mantivessem o equilíbrio da rentabilidade durante todo o ano (CANTON, 2004).

No entanto, a ocupação hoteleira e a dos demais serviços turísticos disponíveis não depende exclusivamente dos turistas de eventos. Brasília conta com outros segmentos de demanda representados pelo turismo cívico, turismo cultural, turismo de negócios, etc. 


\section{MÉTODOS E TÉCNICAS DE PESQUISA}

O presente trabalho foi desenvolvido com dados secundários mediante o levantamento de dados retirados do sistema da empresa estudada.

\subsection{Tipo e descrição geral da pesquisa}

Mattar (2006, p.4) define pesquisa de marketing como uma pesquisa de todo tipo de dado que diz respeito à atividade de marketing da empresa, incluindo elementos abrangidos pela pesquisa de mercado, como: levantamento de mercado, previsão da demanda e de vendas, pesquisas de imagem da empresa e de seus produtos etc.

A análise será realizada através da extração de informações do banco de dados do hotel estudado numa pesquisa explicativa quase experimental.

Os delineamentos quase-experimentais surgiram quando da
necessidade de realizar pesquisas aplicadas, em situações em que
não é possível atingir o mesmo grau de controle que nos
delineamentos experimentais propriamente ditos. Os delineamentos
quase-experimentais tentam atingir um grau de controle próximo ao
dos delineamentos experimentais, para inferir que dado tratamento
teve o efeito pretendido (COZBY, 2003, p.238).

Na pesquisa, será medida a variável dependente - Taxa de unidades habitacionais ocupadas; e as variáveis independentes - Preço efetivamente pago, Eventos no Centro de Eventos Brasil 21, Sazonalidade Mensal e Sazonalidade Diária. 


\subsubsection{Modelo Empírico}

O modelo empírico da pesquisa é mostrada na figura 2.

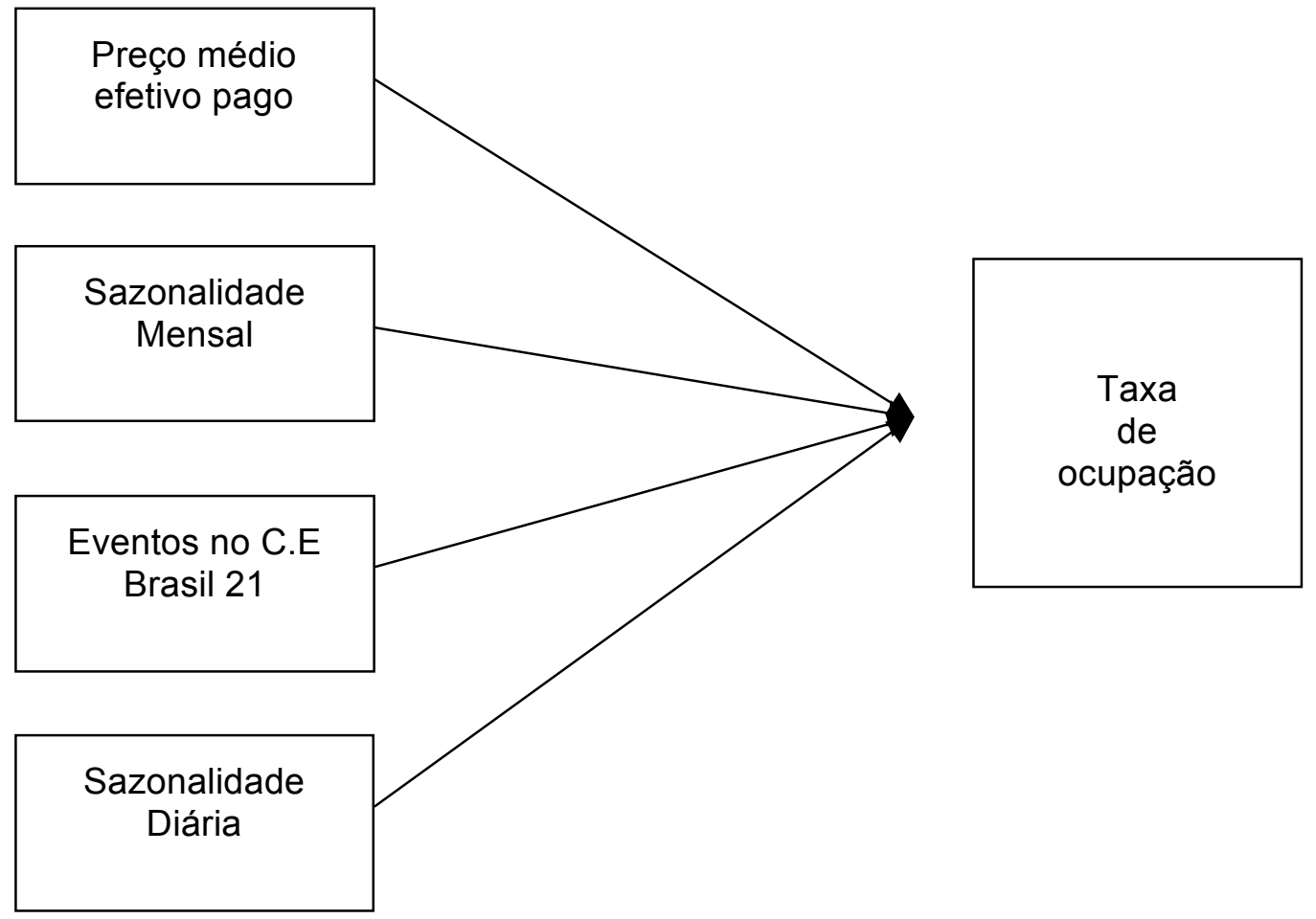

Figura 2: Modelo empírico da pesquisa

Esse modelo foi derivado para um que demonstrasse o controle quase-experimental e pode ser visualizado na tabela 1 :

\section{Tabela 1 - Derivado do Modelo Empírico}

\begin{tabular}{l|l|l}
\hline Saz mensal 1 & Saz diária 1 & TO $=a+b$ Preço+bEventos \\
\hline Saz mensal 1 & Saz diária 2 & TO $=a+b$ Preço+bEventos \\
\hline Saz mensal 2 & Saz diária 1 & TO $=a+b$ Preço+bEventos \\
\hline Saz mensal 2 & Saz diária 2 & TO $=a+b$ Preço+bEventos \\
\hline
\end{tabular}

\subsubsection{Conceitos e Variáveis}

O preço efetivamente pago é definido através do sistema de acordo com a tarifa já acordada no momento da reserva. Cabe ao auditor noturno, conferir as observações de cada reserva e ajustar os valores manualmente, corrigindo o tipo contrato da reserva ou inserindo o valor estabelecido no campo correto. Após o ajuste, é lançado automaticamente em cada reserva com status check-in, o valor prédeterminado. 
A taxa de ocupação depende do total de UH's vendidas. Ela expressa em porcentagem a quantidade diária de unidades habitacionais ocupadas sobre a quantidade total de UH que o hotel dispõe para serem locadas.

A variável eventos baseia-se totalmente na realização (1) ou não (0) de eventos no Centro de Eventos Brasil 21, entenda-se por eventos: congressos, simpósio, seminários, feiras, painéis, palestras, workshops, conferências, etc.

Sazonalidade Mensal e Diária é como se comporta a demanda por serviços hoteleiros em um determinado espaço de tempo, em função da oferta existente. Também foi atribuída uma codificação binária a essas duas últimas variáveis: Sazonalidade Mensal - janeiro (0) / fevereiro, março e abril (1); Sazonalidade Diária sexta, sábado e domingo (0) / segunda, terça, quarta e quinta (1).

\subsection{Caracterização da organização, setor ou área}

A rede Sol Meliá ${ }^{1}$ foi fundada em 1956 por Gabriel Escarrer Juliá em Palma de Mallorca (Espanha) e é a maior companhia hoteleira de férias do mundo, alem de líder absoluta do mercado espanhol, tanto no âmbito de lazer como no de negócios. Dispõe de mais de 300 hotéis em 30 diferentes países de 4 continentes e mais de 35.000 colaboradores. Ocupa o terceiro posto no ranking europeu e o décimosegundo do mundo, sendo líder mundial no ramo de férias, na America Ibérica e no Caribe. Entre suas marcas comerciais estão: Gran Meliá, Meliá Hotels e Resorts, ME by Meliá, Innside, Tryp Hotels, Sol Hotels, Paradisus Resorts e Sol Meliá Vacation Club. Cada uma das marcas é criada para satisfazer um público diferente e exigente, que valoriza a localização estratégica do estabelecimento e os serviços personalizados. O Hotel analisado pertence à marca Meliá, classificado como hotel de luxo equivalente a 5 (cinco) estrelas, geralmente, estrategicamente localizados e com alto padrão nos serviços.

\footnotetext{
${ }^{1}$ Todas as informações acerca da Rede Sol Meliá foram retiradas do site www.solmelia.com e de documentos internos da empresa.
} 
A rede instalou-se no Brasil em 1990 para coordenar a expansão de seus empreendimentos na América Latina. Os hotéis administrados pela Sol Meliá Brasil são de operação e não propriedade. A curto prazo (até 2012) pretende implantar um resort de propriedade na Bahia. Todos as unidades hoteleiras no Brasil respondem à gerência centralizada em São Paulo, chamada internamente de Escritório Corporativo.

Com mais de 50 anos de experiência hoteleira, Sol Meliá iniciou em 2008 um plano estratégico com cinco focos de atuação: Brand equity, Conhecimento e contato do cliente, Desenvolvimento da gestão de ativos, Gestão do talento e potencialização da responsabilidade, e Sustentabilidade.

Em estudo, o Hotel Meliá Brasil 21 localiza-se no Setor Hoteleiro Sul, Quadra 6 Conjunto A, Lote 1, Bloco D em Brasília. Possui um número superior a 150 colaboradores e está estruturado com um gerente geral e um gerente para cada um dos respectivos departamentos: Recepção, Manutenção, Governança, Recursos Humanos, Vendas, Controladoria e Sistemas. Este último, embora subordinado formalmente ao departamento de Controladoria, na prática possui um gerente e responde diretamente à Gerência Geral.

Os outros departamentos que não foram citados, como: Restaurante (incluindo Room service e Frigobar), Lavanderia e Estacionamento são terceirizados. Portanto, seus gerentes e colaboradores não fazem parte do quadro funcional da Sol Meliá, cabendo a administração hoteleira somente a gestão da hospedagem.

\subsection{População e amostra}

O hotel iniciou suas atividades no dia 13 de março de 2003, apresentando um total aproximado de 2620 dias prestando serviços de hotelaria, contados a partir da data de sua inauguração ao dia 10 de julho de 2010. Foi estabelecido para cada dia de funcionamento um preço de venda, bem como gerado no sistema uma tarifa específica para cada reserva baseado em suas observações. Levando em 
consideração os dados acima citados, a população da pesquisa passa a ser o próprio tempo de funcionamento do hotel.

Foi calculado o poder da amostra baseado na família do teste F. Foi escolhido o teste estatístico de regressão múltipla para a análise estatística realizada nesse trabalho. Para realizá-lo, foi feito uma análise do poder, a priori, com tamanho do efeito igual a 0,15 (tamanho médio), com erro de probabilidade $\alpha$ igual a 0,05, e com poder de $93 \%$ com quatro preditores. O resultado apontou um F critico igual a 2,45 e um tamanho da amostra igual a 107 (dias de observação da taxa de ocupação). Como a coleta de dados secundários foi diariamente durante o período de 4 meses, totalizou-se o teste post hoc de 120 dias de observação da taxa de ocupação, sendo mais do que suficiente para haver generalização da amostra.

A amostra da taxa de ocupação (variável dependente) teve média 51,72 (DP = 29). Ou seja, nos 120 dias observados, o hotel obteve média de taxa de ocupação de $52 \%$. Os dias de eventos realizados no Centro de Eventos Brasil 21 representam $64,2 \%$ dos dias analisados, enquanto em $35,8 \%$ desse dias foram identificados como dias sem evento.

A sazonalidade mensal foi classificada como alta ou baixa temporada. Sendo que, dos meses estudados (janeiro, fevereiro, março e abril), somente o mês de janeiro foi enquadrado como baixa temporada. Portanto, $25,8 \%$ dos dias analisados configuram baixa temporada e $74,2 \%$ desses dias respondem à alta temporada.

Em relação à sazonalidade diária, encaixam-se nessa variável, o padrão identificado em Brasília de alta ocupação e maior trânsito de hóspedes nos dias da semana (89\%), especificamente, de segunda à quinta-feira e consequentemente às sextas, sábados e domingos, os hotéis da cidade possuem um nível menor de demanda por seus serviços $(25 \%)$. 


\subsection{Caracterização dos instrumentos de pesquisa}

Essa pesquisa foi realizada utilizando-se de dados secundários internos, ou seja, proveniente da empresa estudada, conseguidos por intermédio do sistema CM Soluções - Visual (navegação através do Sistema Operacional Windows). Através da coleta e análise de vários relatórios já citados e da conferência e validação dos mesmos no próprio sistema, foi elaborada uma planilha de MS-Excel com as informações específicas para a realização da pesquisa, onde foram analisados a variável dependente - Taxa de ocupação diária e as variáveis independentes - Preço médio efetivo pago, Sazonalidade Mensal, Eventos no Centro de Eventos Brasil 21 e Sazonalidade Diária.

\subsection{Procedimentos de coleta e de análise de dados}

Após autorização verbal da gerência de recepção e geral do hotel, foi montada uma planilha com os dados obtidos através de análises e compilações de diversos relatórios. Entre eles, relatório de atividade mensal, controle mensal de ocupação, relatório mensal de situação, faturamento mensal, entre outros.

A planilha ordena a quantidade de unidades habitacionais ocupadas por dia e por categoria de UH expressos em números cardinais, o preço padrão referencial de venda (minimum rate) de cada categoria de UH por dia (em reais), preço efetivo pago pelo hóspede por diária expressos em reais, a percentagem de taxa de ocupação diária do hotel, valor da diária média do hotel por dia (em reais) e a realização ou não de eventos no Centro de Eventos Brasil 21 (por dia).

Foram realizadas duas regressões com as mesmas variáveis. A diferença entre elas encontra-se no fato da segunda regressão ter as variáveis independentes subdivididas. Na segunda regressão, a variável sazonalidade diária aparece embutida na sazonalidade mensal, ou seja, o mês de janeiro (classificado como baixa temporada) possui dias de maior ocupação (de segunda-feira à quinta-feira) e dias de menor ocupação (sexta-feira, sábado e domingo). 
Para ser possível a realização da análise de regressão múltipla, dois pressupostos são exigidos:

a) A variável dependente taxa de ocupação, necessariamente, deverá ser identificada como uma variável normal. Como ilustra a tabela 2 , baseado no teste KS Z de valor 1,00 e p > 0,05, considera-se a hipótese nula que a variável dependente é normal, portanto atende-se uma das exigências para a realização da análise de regressão múltipla.

\begin{tabular}{l|r|rr}
\hline \multicolumn{3}{c}{ Tabela 2 - Teste Kolmogorov-Smirnov Z } \\
\hline & $\begin{array}{c}\text { Taxa Ocup. } \\
(\%)\end{array}$ & $\begin{array}{c}\text { Preço efetivo pago } \\
\text { (R\$) }\end{array}$ \\
\hline Kolmogorov-Smirnov Z & 1,00 & 0,74 \\
Asymp. Sig. (2-tailed) & 0,27 & 0,64 \\
\hline
\end{tabular}

a. Distribuição Teste é Normal.

Fonte: Coleta de dados

b) A colinearidade entre as variáveis independentes Diária Média Efetiva, Sazonalidade Diária, Eventos no Centro de Eventos Brasil 21 e Sazonalidade Mensal, foi baixa apresentando um VIF $<2$.

Além disso, na análise de regressão múltipla, os resíduos devem apresentar homocedasticidade para que os parâmetros da regressão sejam confiáveis. Esse pressuposto foi sutilmente violado pois os resíduos apresentaram ligeira heterocedasticidade,conformeográfico1.

Variável Dependente: Taxa Ocup.Geral (\%)

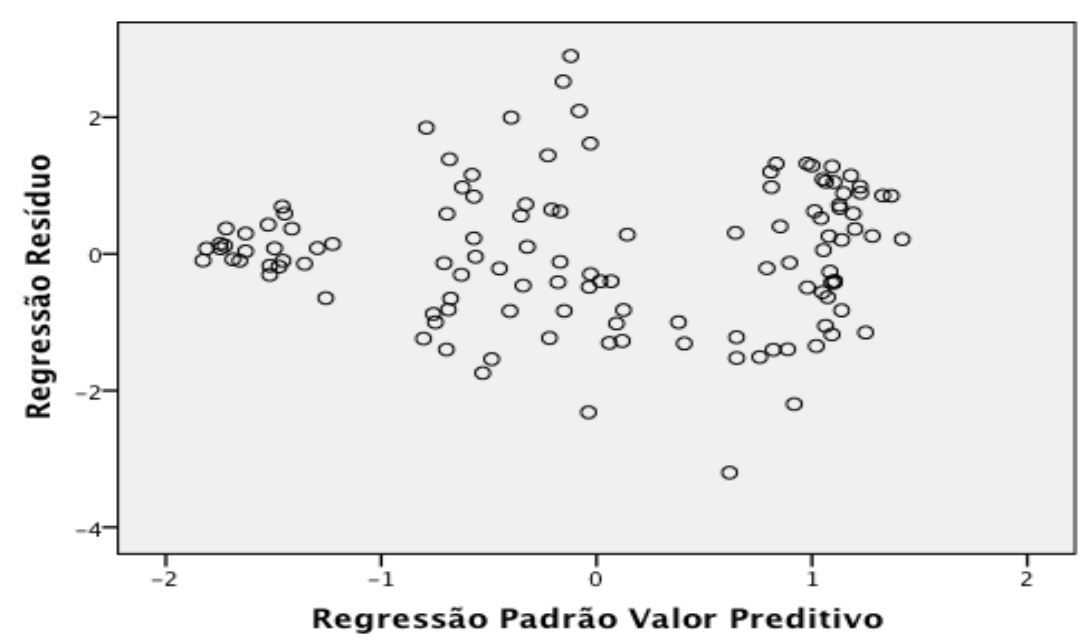

Gráfico 1 - Resíduos

Fonte: Coleta de Dados 


\section{RESULTADOS E DISCUSSÃO}

Nesta seção serão apresentados os resultados advindos da pesquisa realizada. As indagações levantadas são: (1) Como se comporta a taxa de ocupação do Hotel Meliá Brasil 21? (2) Será que a sazonalidade mensal ou diária, eventos e preço pago explicam a taxa de ocupação? (3) Será que a realização de eventos e preço pago influenciam a taxa de ocupação de maneira distinta a depender da sazonalidade mensal e diária?

\subsection{Variação da taxa de ocupação}

As variações representadas no gráfico 2 representam o comportamento da variável independente taxa de ocupação ao longo dos 4 meses estudados. Verifica-se que ela teve picos altíssimos, chegando à máxima 99,62\%

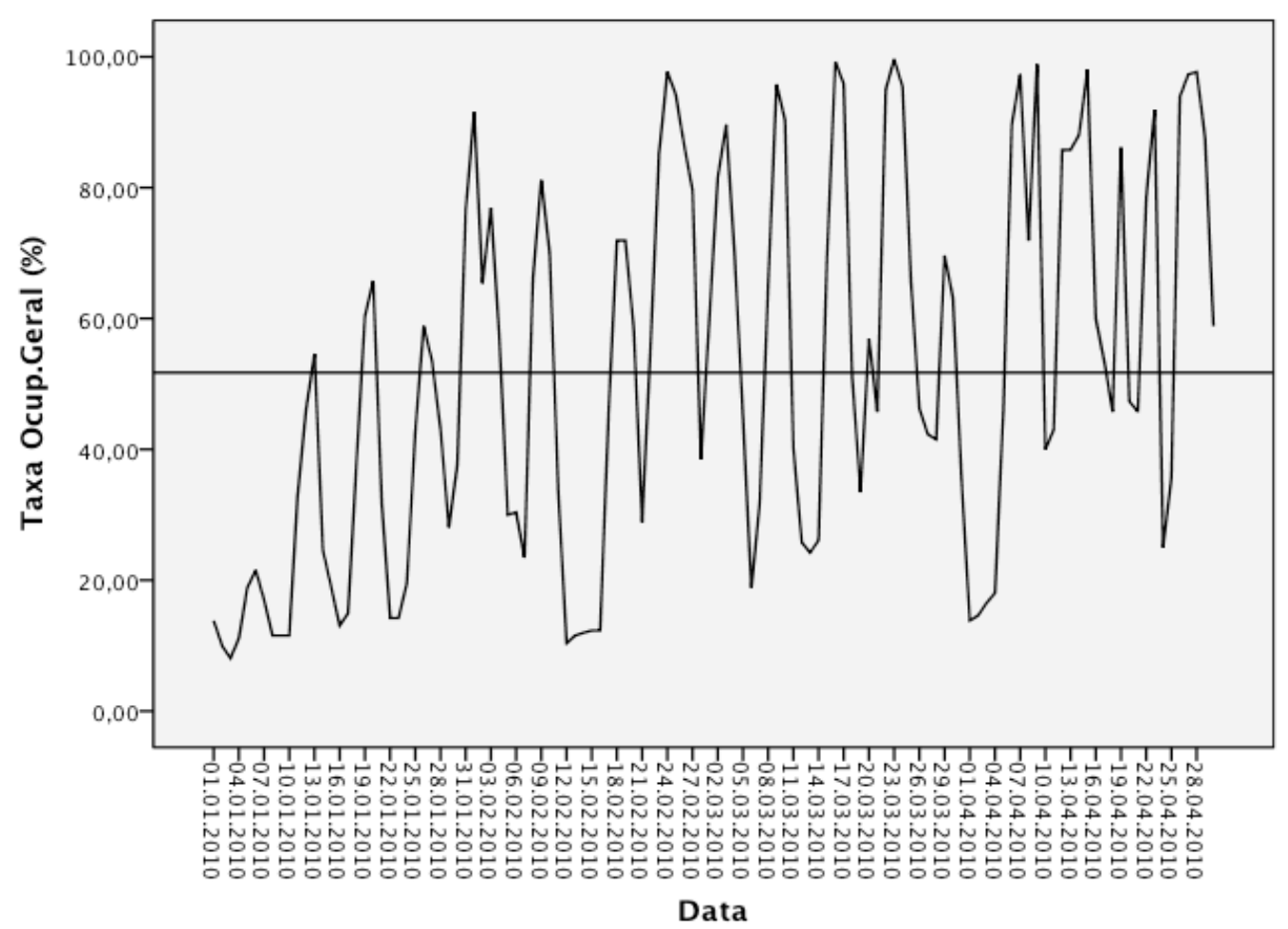

Gráfico 2 - Mapa Sequencial

Fonte: Coleta de Dados 
É possível ter essa reação do gráfico 2 de altas e baixas por causa da sazonalidade existente nos períodos de final de semana e meses de baixa ocupação.

\subsection{Regressão entre sazonalidade diária e mensal, preço e eventos na taxa de ocupação}

Observando os resultados da primeira regressão, obtem-se a seguinte explanação:

O resultado da análise de regressão apresentou um $\mathrm{R}^{2}=0,626$. Isso significa que a análise consegue explicar $62,6 \%$ das variações existentes no gráfico 2 .

\begin{tabular}{|c|c|c|c|c|c|c|c|}
\hline \multirow[b]{2}{*}{ Modelo } & \multicolumn{2}{|c|}{$\begin{array}{l}\text { Coeficientes } \\
\text { Não-padrão }\end{array}$} & \multirow{2}{*}{$\begin{array}{c}\begin{array}{c}\text { Coeficientes } \\
\text { Padrão }\end{array} \\
\text { Beta } \\
\end{array}$} & \multirow[b]{2}{*}{$\mathrm{t}$} & \multirow[b]{2}{*}{ Sig } & \multicolumn{2}{|c|}{$\begin{array}{c}\text { Estatísticas de } \\
\text { Correlação }\end{array}$} \\
\hline & B & $\begin{array}{c}\text { Erro } \\
\text { Padrão }\end{array}$ & & & & Tolerância & VIF \\
\hline (Constante) & $-5,46$ & 8,30 & & $-0,66$ & 0,51 & & \\
\hline $\begin{array}{l}\text { Sazonalidade } \\
\text { Diária }\end{array}$ & 19,45 & 3,92 & 0,33 & 4,96 & 0,00 & 0,72 & 1,39 \\
\hline $\begin{array}{l}\text { Sazonalidade } \\
\text { Mensal }\end{array}$ & 6,28 & 4,68 & 0,10 & 1,34 & 0,18 & 0,65 & 1,55 \\
\hline Eventos* & 30,61 & 4,35 & 0,51 & 7,04 & 0,00 & 0,62 & 1,60 \\
\hline $\begin{array}{l}\text { Preço efetivo } \\
\text { pago }(\mathrm{R} \$)\end{array}$ & 0,08 & 0,03 & 0,16 & 2,37 & 0,02 & 0,68 & 1,46 \\
\hline
\end{tabular}

a. Variável Dependente: Taxa Ocup.Geral (\%)

Fonte: Coleta de Dados

Nota-se na tabela 3 que a variável dependente taxa de ocupação possui duas fortes preditoras: as variáveis independentes sazonalidade diária e eventos, sendo esta última a maior preditora da taxa de ocupação. Ou seja, quando presente (código 1 para a realização de evento) a variável independente eventos $(B=30,61 ; p<0,05)$, maior a variável dependente taxa de ocupação; e quando presente (dias da semana: seg a qui) a variável independente sazonalidade diária $(B=19,45 ; p<0,05)$, maior a taxa de ocupação.

Segundo Canton (2001, p.301) a hotelaria investe consideravelmente e estrategicamente no setor de eventos, os núcleos potencialmente turísticos passaram a entender a importância dos eventos como alavancador da demanda turística. 


\subsection{Regressão entre preço e eventos na taxa de ocupação com o controle das sazonalidades}

Já na segunda regressão, o $R^{2}$ varia entre 0,088 e 0,52 . Sendo possível o entendimento de até $52,9 \%$ do gráfico 2 .

$\mathrm{Na}$ tabela 4, percebe-se que nos casos onde Sig $<0,05$ indica que houve relação preditiva. Demonstrando significância (entenda-se poder de influência na variável dependente taxa de ocupação) nos dias que acontecem eventos no Centro de Eventos Brasil 21 e Sazonalidade Diária (Segunda a Quinta).

Tabela 4 - Coeficientes ${ }^{\mathrm{a}}$ Regressão 2

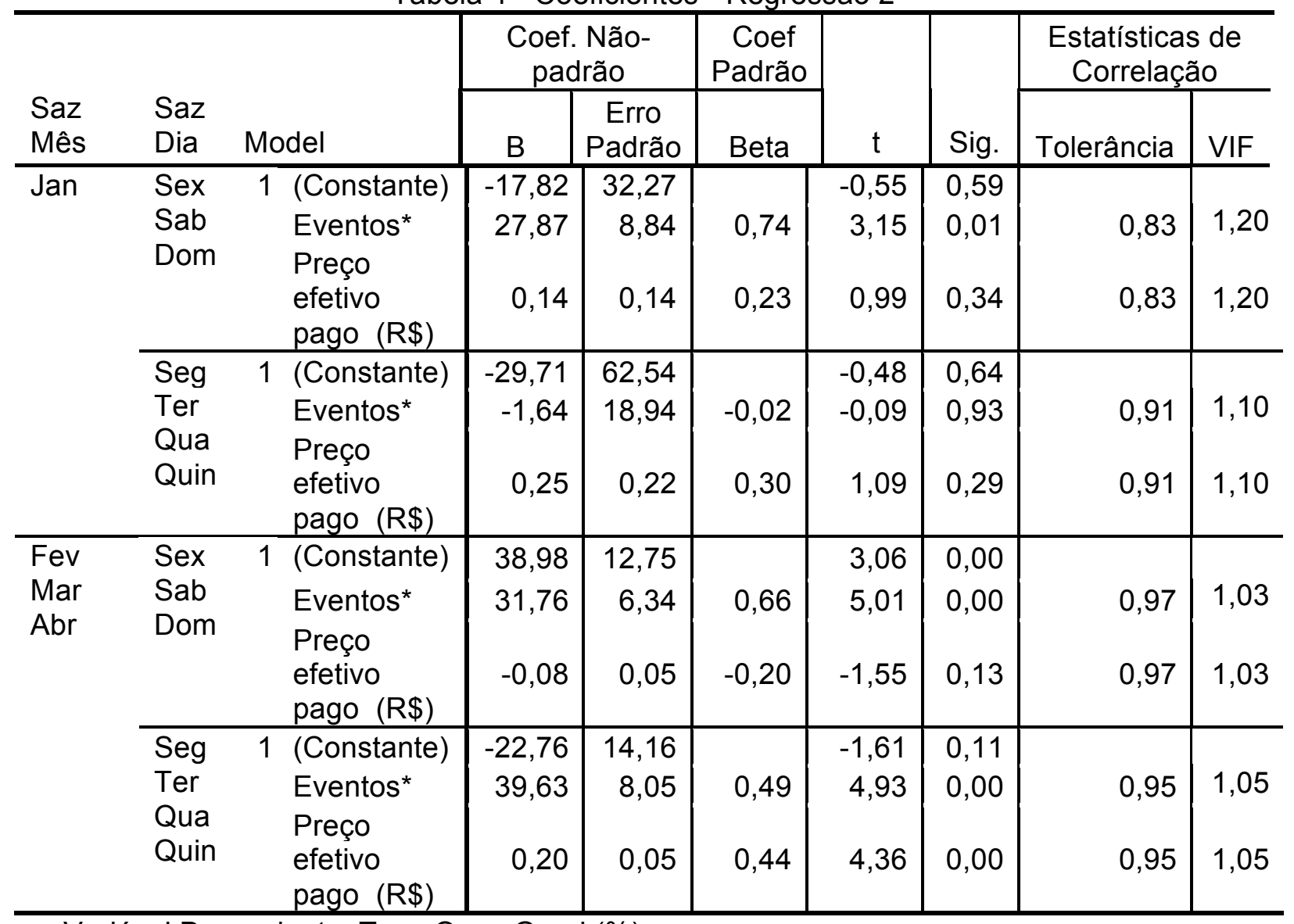

a. Variável Dependente: Taxa Ocup.Geral (\%)

Fonte: Coleta de Dados

Nota-se na tabela 4 que as preditoras da variável dependente taxa de ocupação são: a variável independente eventos na sexta, sábado ou domingo de janeiro $(B=27,87$; $p<0,05)$; a variável independente eventos na sexta, sábado ou domingo de fevereiro, março e abril $(B=31,76 ; p<0,05)$; a variável independente eventos na segunda, terça, quarta ou quinta de fevereiro, março e abril $(B=39,63 ; p<0,05)$; a 
variável independente preço na segunda, terça, quarta ou quinta de fevereiro, março e abril $(B=0,20 ; p<0,05)$.

Ou seja, a regressão aponta como significante com capacidade de predição da taxa de ocupação durante o mês de janeiro, aos finais de semana ${ }^{2}$, a realização de eventos. E durante os outros três meses estudados - fevereiro, março e abril, a maior significância está, também, na ocorrência de eventos, sejam realizados aos finais de semana ou durante a semana. Este último, aparece com maior força, sendo responsável pelo aumento da taxa de ocupação na ordem de 39,63 enquanto aos finais de semana, os eventos aumentam na ordem de 31,76.

É possível verificar, também, que durante a semana dos meses de fevereiro a abril, a diária média paga pelo hóspedes teve impacto na taxa de ocupação, mesmo sendo na ordem de apenas 0,20. Portanto, um aumento na diária poderia representar um aumento pequeno na taxa de ocupação quando comparado à ocorrência de eventos. O aumento do preço ocorre quando há pouca sensibilidade ao preço pago (CRESSMAN JR., 2002) conforme figura 3, seja em função do status que o Hotel estudado oferece por ser um empreendimento de luxo e estar categorizado como um hotel cinco estrelas ou pelo fato da maioria dos reservantes ser empresas, agências e operadoras, que nem sempre escolhem os menores preços ou, ainda, pela lealdade do consumidor em relação à marca (BOTELHO; URDAN, 2005).

\begin{tabular}{|c|c|}
\hline Estrutura de custos & Decisão de precificação pela maximização do lucro \\
\hline Mais fixos/menos variáveis & Reduzir preços \\
\hline Mais variáveis/menos fixos & Aumentar preços \\
\hline Sensibilidade do consumidor a preço & Decisão de precificação pela minimização do lucro \\
\hline $\begin{array}{l}\text { Mais sensivel a preço } \\
\text { (menos sensivel a valor) }\end{array}$ & Reduzir preços \\
\hline $\begin{array}{l}\text { Menos sensivel a preço } \\
\text { (mais sensivel a valor) }\end{array}$ & Aumentar preços \\
\hline
\end{tabular}

Figura 3 - Processo de precificação e definição de lucros Fonte: HSM Management, 2002.

No segmento hoteleiro, os eventos agem como impulsionadores da ocupação hoteleira à medida que trazem hóspedes para usufruírem do hotel. Assim, quando

\footnotetext{
${ }^{2} \mathrm{O}$ aparecimento do termo finais de semana refere-se sempre às sextas, sábados e domingos.
} 
um evento é realizado em um hotel há a possibilidade de concentrar parte de seus participantes na ocupação das unidades habitacionais do hotel (ALVARES, 2001), portanto, os eventos também funcionam como uma forma de equilíbrio de sua ocupação nos períodos de baixa temporada, e uma fonte de receita pois seus participantes utilizarão, também, serviços de outros setores do hotel além do setor de hospedagem.

Existe uma relação forte entre eventos, turismo e hotelaria. De acordo com o presidente do Fórum dos Convention \& Visitors Bureau do Brasil (FCVBB) em 2003, Roberto Gheler, a realização de eventos no país gera $\mathrm{R} \$ 32$ bilhões $(3,1 \%$ do PIB Nacional) ao ano e R $\$ 4,2$ bilhões em impostos. Os eventos gerados em Brasília estão alavancando economicamente a cidade, incluindo a ocupação dos hotéis e a geração de emprego e renda. A promoção de eventos funde-se à atividade turística e hoteleira, para as cidades que possuem uma ociosidade no setor hoteleiro, como é o caso de Brasília, onde o turismo de eventos vem ao encontro da necessidade de se aumentar a taxa ocupacional dos hotéis (ZANINI; FARIA, 2003).

Estudiosos como Tomazzoni, Bühler e Simão (2008) realizaram pesquisas envolvendo a realização de eventos e o turismo da região de Bento Gonçalves e encontraram um resultado voltado à importância da realização de eventos pois elas agregam valor ao produto turístico e reduzem os efeitos da sazonalidade. De modo semelhante, Ignarra (2007) pesquisou os eventos turísticos e seus impactos na hotelaria paulistana, concluindo que a maior parte do eventos que ocorrem em São Paulo, são realizadas em hotéis, aumentando consideravelmente as taxas de ocupação dos hotéis estudados, com exceção de um hotel da amostra que possuía a maior tarifa média praticada. 


\section{CONCLUSÕES E RECOMENDAÇÕES}

Dentre os objetivos específicos, este estudo pôde plenamente atingir os objetivos propostos, visto que analisou a relação preditiva entre preço pago, realização de eventos e sazonalidade na taxa de ocupação de unidades habitacionais do hotel, verificando que existe uma grande relação preditiva entre a realização de eventos e a sazonalidade na taxa de ocupação.

A pesquisa também analisou a relação preditiva entre preço pago e realização de eventos na taxa de ocupação de unidades habitacionais do Hotel, em diferentes períodos de sazonalidade, chegando à conclusão que ambas são capazes de predizer a taxa de ocupação do Hotel, sendo o preço de menor intensidade de impacto que os eventos.

O resultado geral apontou que a variável independente impulsionadora do aumento da variável dependente taxa de ocupação é a realização de eventos, relacionada ao dia e mês escolhido para a realização do evento (sazonalidade diária e mensal).

Deve-se ressaltar que, o estudo considerou os resultados coletados apenas no Hotel Meliá Brasil 21, portanto, as conclusões obtidas são limitadas a este hotel, não podendo ser generalizadas para todos os hotéis de Brasília.

Encontrou-se limitações neste trabalho no tamanho da amostra pois não foram compreendidos os meses do segundo semestre do ano, que geralmente é mais movimentado e aquecido economicamente. Inclui-se nas limitações o ano analisado (2010), por ser ano eleitoral em que serão eleitos a presidência da República e governadores. Tal fato pode ter influência a ocorrência de eventos ligados ao movimento político, que não ocorreria com a mesma frequência em outros anos.

Os resultados obtidos apresentam-se com coerência pois Brasília é uma cidade de negócios, onde são realizados feiras, congressos, reuniões, etc. Além de ser 0 centro das tomadas de decisão do país. 


\subsection{Considerações gerencias}

Sugere-se à gerência do Hotel Meliá Brasil voltar seu foco para eventos ocorridos no Centro de Eventos Brasil 21 e até mesmo para eventos ocorridos na cidade de Brasília. Deve-se dar atenção aos grupos ou pacotes que podem ser fechados com os participantes dos eventos.

Faz-se necessária a comunicação integrada entre o departamento de eventos do hotel e o Centro de Eventos Brasil 21, para organizar de maneira eficaz a captação de eventos e oferecimento dos serviços do meio de hospedagem, já que o próprio hotel Meliá não tem capacidade para promoção de grande eventos. Com a hospedagem dos participantes do evento, a taxa ocupacional estará sempre alta, reduzindo o período de sazonalidade.

Procurar sempre fazer pacotes com melhores preços para os participantes do evento, evitando que unidades habitacionais fiquem vazias no período do evento; ter um programa de pós-venda, para saber se o serviço satisfez o cliente; fazer relatório de perdas, procurando saber porque tal evento foi realizado em um determinado hotel; são ações que podem ser tomadas com vista a realizar melhorias para que a empresa não perca potenciais hóspedes.

Por fim, os hotéis devem procurar fazer alianças estratégicas entre si, procurando captar eventos maiores em conjunto, dividindo a hospedagem dos participantes; repassar a hospedagem, para hotéis parceiros, quando o hotel estiver com lotação máxima; procurar sempre saber da atuação do governo, em relação ao turismo; solicitar e dar apoio nas questões que possam trazer melhorias para 0 aproveitamento do turismo de negócios para Brasília.

Futuras pesquisas podem incluir a influência da proximidade do Hotel a grandes centro de convenções e parques que abrigam eventos, tomando como base a realização de eventos nesse locais e na cidade de Brasília em geral e seu impacto na taxa de ocupação do Hotel e também a razão da escolha (por clientes) de um hotel específico em detrimento de tantos outros hotéis localizados no Setor Hoteleiro Sul. 


\section{REFERÊNCIAS}

ALVARES, D. F. Setor de Eventos na Hotelaria: Promoção, uma alternativa rentável. (Trabalho de Conclusão de Curso). ECA - Escola de Comunicação e Artes. Curso para Bacharel em Turismo, Universidade de São Paulo, São Paulo, 2001.

ALMEIDA, D.C. Levantamento das estratégias dos hotéis goianienses na captação de eventos e seus impactos na ocupação. Dissertação (Pós-graduação em Gestão da Hospitalidade). Universidade de Brasília, 2004.

AVLONTIS, G.J.; INDOUNAS, K.A. Pricing objectives and pricing methods in the services sector. Journal of Services Marketing, p.19, 2005.

AGGETT, M. What has influenced growth in the UK's boutique hotel sector? International Journal of Contemporary Hospitality Management, p. 39, 2007.

BERNARDI, L. A. Política e formação de preços: uma abordagem competitiva, sistêmica e integrada. São Paulo: Atlas, p. 41-198, 1966.

BOTELHO, D.; URDAN, A. T. Lealdade à marca e sensibilidade ao preço: um estudo da escolha da marca pelo consumidor. Revista de Administração Contemporânea vol.9 n.4, Outubro-Dezembro, 2005.

BRASILIATUR. Disponível em: <http://www.brasiliatur.df.gov.br>. Acesso em 01 de mai. 2010.

BRITTO, J.; FONTES, N. D. Turismo e Eventos: Instrumento de Promoção e Estratégia de Marketing. Turismo em Análise. São Paulo,1997.

BRUNI, A. L.; FAMÁ, R. Gestão de custo e formação de preço: com aplicação na calculadora HP12C e Excel. São Paulo: Atlas, p.123-142, 2003.

CANTON, A. M. Eventos. In: ANSARAH, M. G. R. (Org.). Turismo: como aprender, como ensinar. V.2. São Paulo: SENAC, 2004.

CARVELL, S. A.; QUAN, D.C. Exotic reservations - low prices guarantee.

International Journal of Hospitality Management, p.18, 2008. 
CHAN, E. S. W.; WONG, S. C. L. Hotel selection: when price is not the issue. Journal of Vacation Marketing, 2006.

CHON, K.; SPARROWE, R. Hospitalidade Conceitos e Aplicações. São Paulo: Pioneira Thomsom Learning, 2003.

COGAN, S. Custos e preços: formação e análise. São Paulo: Pioneira, p.56-75, 1999.

COZBY, P. C. Métodos de pesquisa em ciências do comportamento. São Paulo: Atlas, 2003.

CRESSMAN JR., G. E. A Definição de Preço na Prática. HSM Management 33, Julho-Agosto, 2002.

EMBRATUR. Disponível em: <http://www.embratur.gov.br>. Acesso em 01 de mai. 2010

GOELDNER, C. R.; RITCHIE, J. R.; BRENT E MCINTOSH, R. W. Turismo Princípios, Práticas e Filosofias. Porto Alegre: Bookman, 2002.

HORNGREN, C. T; DATRA, S. M; FOSTER, G. Contabilidade de Custos: uma abordagem gerencial. São Paulo: Prentice Hall, p.112, 2004.

IGNARRA, L. R. Dinâmica dos eventos turísticos e seus impactos na Hotelaria Paulistana. Dissertação (Doutorado em Ciência da Comunicação). ECA, Universidade de São Paulo, 2007.

JEFFREY, D; BARDEN, R. R. D. An Analysis of the Nature, Causes and Marketing Implications of Seasonality in the Occupancy Performance of English Hotels. Tourism Economics. Vol. 5 No 1, p 28, 1999.

KANDAMPULLY, J.; SUHARTANTO, D. The customer loyalty in the hotel industry: the role of customer satisfaction and image. International Journal of Contemporary Hospitality Management, p.38, 2000.

KOTLER, P; ARMSTRONG, G. Princípios de Marketing. Rio de Janeiro: Prentice Hall, p.19 -189, 1993.

KOTLER, P.; KELLER, K. L. Administração de Marketing. 12.ed. São Paulo: Pearson Prentice Hall, 750 p., 2006. 
LAGE, B. H. G.; MILONE, P. C. Fundamentos econômicos do turismo. In: LAGE, B. H. G.; MILONE, P. C. (Org.) Turismo: teoria e prática. São Paulo: Atlas, 2000.

LARA, S. B. Marketing \& Vendas na hotelaria. São Paulo: Futura, p.29-89, 2001.

LEPSCH, S. L.; SOUZA, E. B. Gestão operacional de marketing. In: E. Pinto (Org.) Gestão empresarial: casos e conceitos de evolução organizacional. São Paulo: Saraiva, p. 167-192, 2007.

LOCKYER, T. Understanding the dynamics of the hotel accommodation purchase decision. International Journal of Contemporary Hospitality Management, p. 85, 2005.

LOVELOCK, C. H. Services Marketing. 3. ed. Prentice-Hall, p.106-115, 1996.

MATTAR, F. N. Pesquisa de Marketing: edição compacta 4.ed. São Paulo: Altas, p.4-45, 2006.

NAGLE, T. T.; HOLDEN, R. K. The Strategy and Tactics of Pricing. Prentice-Hall, p. 102, 1995.

PEREIRA, F. H. Metodologia de formação de preço de venda para micro e pequenas empresas. 2000. Dissertação (Mestrado em Engenharia da Produção). Universidade Federal de Santa Catarina, Florianópolis, p. 42, 2000.

TEIXEIRA, R. M. Gestão de Marketing em Pequenos Empreendimentos Hoteleiros. Revista Turismo em Análise, vol 15 n. 1. USP, p. 136-201, 2004.

TEIXEIRA, M. S. G. O terciário na estrutura produtiva do Ceará: uma análise da organização do setor de turismo. Mestrado. Universidade Federal do Ceará. Fortaleza, 1991.

TOMAZZONI, E. L.; BÜHLER, L.V.; SIMÃO, S. Os retornos dos eventos técnicos e científicos para o turismo e para a economia do município de Bento Gonçalves (RS). V Seminário da Associação Nacional de Pesquisa e PósGraduação em Turismo, 2008.

SARDINHA, J. C. Formação de preço: a arte do negócio. São Paulo: Makron Books, p. 35, 1995.

SENAC. Eventos: oportunidades de novos negócios. SENAC, São Paulo, 2000. 
WATCHRAVESRINGKAN, K.; YURCHISIN, J. A structural analysis of value orientations, price perception and ongoing search behavior: a cross-cultural study of American and Korean consumers. International Journal of Consumer Studies, p.57, 2007.

WEISE, A. D. Fatores que influenciam a avaliação de hotéis. VI Seminário Internacional de Lares. São Paulo, p.5, 2006. Disponível em:

$<$ http://www.lares.org.br/2006/artigo\%20andreas\%20weise\%20Fatores\%20que\%20influencia $\mathrm{m} \% 20 \mathrm{a} \% 20$ avalia\%E7ao\%20de\%20.pdf>. Acesso em 01 de jun. 2010

YAN, R. Pricing strategy for companies with mixed online and traditional retailing distribution markets. Journal of Product \& Brand Management, p.62, 2008.

ZANINI, C. R.; FARIA, A. L. L. Eventos: uma ferramenta para o desenvolvimento turístico. Revista de Estudos Turísticos, 2003. 


\section{APÊNDICES}

\section{Apêndice A - Organograma do Hotel Meliá Brasil 21}

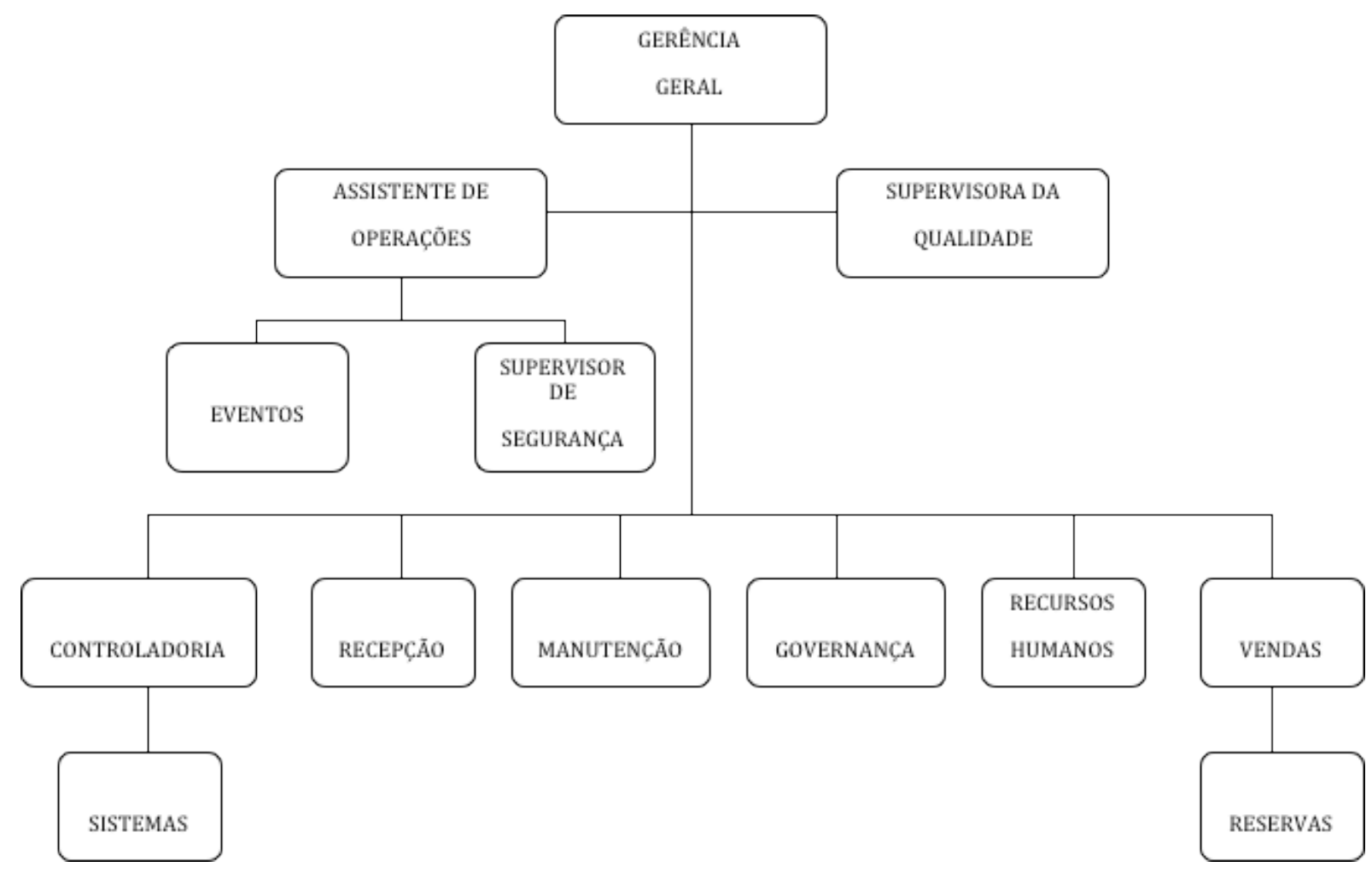

